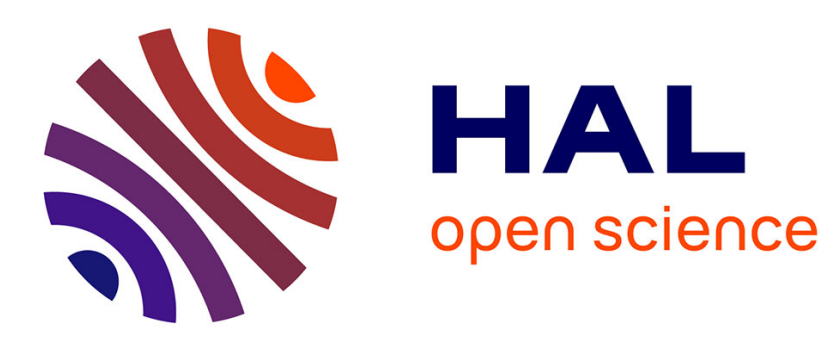

\title{
Take into account knowledge constraints for design of TEL environments in medical education
}

\author{
Vanda Luengo
}

\section{To cite this version:}

Vanda Luengo. Take into account knowledge constraints for design of TEL environments in medical education. The 8th IEEE International Conference on Advanced Learning Technologies, 2008, Spain. pp.839. hal-00593047

\section{HAL Id: hal-00593047 https://hal.science/hal-00593047}

Submitted on 13 May 2011

HAL is a multi-disciplinary open access archive for the deposit and dissemination of scientific research documents, whether they are published or not. The documents may come from teaching and research institutions in France or abroad, or from public or private research centers.
L'archive ouverte pluridisciplinaire HAL, est destinée au dépôt et à la diffusion de documents scientifiques de niveau recherche, publiés ou non, émanant des établissements d'enseignement et de recherche français ou étrangers, des laboratoires publics ou privés. 


\title{
Take into account knowledge constraints for design of TEL environments in medical education
}

\author{
Luengo Vanda \\ University Joseph Fourier, Laboratoire LIG, Grenoble, France \\ Vandal.luengo@imag.fr
}

\begin{abstract}
In this paper we present an approach, based on exploiting and modeling empirical knowledge, for design an adaptive intelligent tutoring system in medical education. We present our learning knowledge design constraints and their related computer representations. We conclude with the possibilities of our approach and their perspectives.
\end{abstract}

\section{Introduction}

A critical issue in the design of TEL for medical training is the relationship between technology and training effectiveness. Indeed, sometimes the training device has to be as realistic as possible [6] and other times the device does not need to recreated this level of 'realism', like in the case of the bench models for the minimal invasive surgery [2]. Also, sometimes TEL environments need an appropriate learning situation to improve a kind of learning, but sometimes learning situations have to use specific tools to be efficient [6].

For us the main challenge is to propose computer tools, based on educational and cognitive science theories, to re-think the TEL system in order to achieve adequate apprenticeship realism and to organize the feedback.

Our objective in this paper is to show how we design a computer architecture and methodology in order to take into account knowledge forms and learning situations constraints.

\section{Constraints framework for computer representation}

For the design of our TEL environments in medical education, we use some computer representations. For choose these computer representations we take into account knowledge and learning characteristics.

Indeed, in our case Vadcard [8] proposes three types of knowledge that are at stake during this learning activity: declarative, perceptivo-gestural and empirical.

Besides, in our case, the learning situations are the problem solving situations. The fidelity of problems in this approach is not a material fidelity but is posed in terms of an epistemic fidelity. It thus requires to transform the working situations into training-oriented situations.

The main important criteria that are considered to build these problems are the relevant variables for learning, also called "didactical variables" [3] and the "milieu" for learning gathers all the elements of the environment that are linked to the epistemic part of learning.

This last component will allow the problem-solving situation to "react" in a relevant way, according to the targeted knowledge. The feedback accompanies the subject in the learning process, by provoking reinforcements, destabilisations, hints, scaffolding...

\section{TELEOS, a Computer learning systems in orthopedic surgery}

We have developed a multi-agent system, Javatechnology-based. Each agent is built in relation to the knowledge learning constraints.

\subsection{Student learning resources}

For these kinds of agents the computer model has to be a description of world (representation of objects, their relationships and their feedbacks). It is based in reference to a knowledge whit epistemic specificity [8].

In our case, we developed different agents related to knowledge types. Declarative knowledge is adapted to multimedia courses. Empirical and gestural knowledge is adapted to simulators, and clinical cases that give more information about empirical knowledge for destabilizing or reinforcing it. 
3.1.1. Simulator. We have a simulation for the training of the percutaneous placement of screws in the pelvis. The user manipulates 3D pelvis, with skin and landmarks. It is possible to place a pin and to introduce it in the body. The actions are free, which means that the allowed movements are continuous, and it is possible to return back in the activity. At any time the user can ask for four X-ray controls. The available orientations correspond to the orientations used in real situation.

3.1.2. Clinical cases. The role of the Clinical Case agent is to illustrate the consequences of a give proposed trajectory. We can propose an example of a set of clinical cases related with some images takes in pre-operation phase. We can find some pertinent information related to different phases (before, during and after the operation). One pedagogical feedback is for example a film part during the operation.

3.1.3. Web Courses. For this part we use ontology with a set of rule based in owl language because this knowledge is declarative and complete. We have developed a semantic web module. This module proposes not only syntactic links, but also semantic ones; it allows the redirection to precise and relevant parts of the online course.

\subsection{Computer knowledge models}

Like presents by Russel [7], use only first-order logic to cope with a domain such medical diagnosis fails for three main reasons: "Lazinnes, too much effort to list the complete set of antecedents or consequents needed to ensure an exception-less rule and too hard to use such rules. Theoretical ignorance, medical science does not have a complete theory for the domain. Practical ignorance, even if we know all rules, we might be uncertain about a particular patient because all necessary tests have not been or cannot be run".

The diagnostic and feedback in computer learning systems have the same features. For us, is necessary that the computer model take into account the constraints linked to the empirical and incomplete characteristics of this type of systems.

3.2.1. Knowledge domain model. It is related to the information about the conceptions engaged by the user for solve a problem. For didactical analyze and knowledge representation we adopt the $\mathrm{cK} \phi$ model [1]. It defines a conception as: a set of problems (P); a set of operators $(\mathrm{R})$ involved in the solutions of problems from $\mathrm{P}$; representation system (L) allowing the representation of $\mathrm{P}$ and R a set of control structure $(\Sigma)$.

For example [8], in order to solve the problem $p_{a}$ "insert a pin in the case of a pelvis fracture, normal bone", it is necessary to apply several operators $\mathrm{R}$ (example: $r 6$ "take inlet X ray"). Several elements of controls $\Sigma$ are identified to validate the operator r7. For example $\sigma 14$ : "if the pin is too down on the inlet view, then it is too ventral and too caudal on he patient". The assessment of the use of a relevant control element depends on the problem context.

Our didactical research distinguishes the controls in relation to the kind of knowledge presented above (2). This knowledge extraction has two important characteristics: the knowledge extraction is empirical, it come from the study of prescribed and real situations with observations and interviews; there is a causal relation between the knowledge elements, i.e. the controls come from a set of operators, and the operators are defined in relation to a set of problems.

For these reasons we decide to model this agent with a bayesian network.

3.2.2. Diagnostic model. It objective is to make sense of a user actions and events in order to understand their conceptions of the represented world.

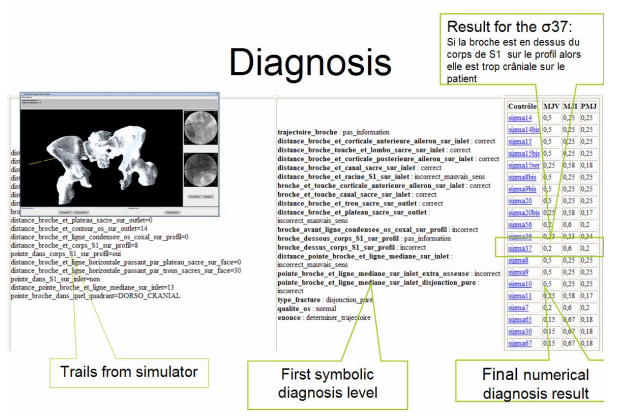

Figure 1, diagnosis result.

The diagnosis system calculates the values of the "situation" variables (the pin position on the bone, for example) from the student's learning traces during interaction with the simulator. This first diagnosis is a symbolic level; it applies a set of IF-THEN rules because this knowledge is factual and complete.

The second kind of information (conceptions) is empirical and it has to change during the user action. This part of our computer model has to be able to handling this uncertain and temporal dimension. Therefore, we decide to model this part with a temporal Bayesian network [4], this second diagnosis level is numerical.

Every element of knowledge has three possible states: Used_Invalid, Used_Valid, and Didn't_Use. This diagnosis (see figure 1) evolves during the interaction with the learning resources.

3.2.3. Didactical feedback model. The objective for this agent is to propose the best feedback from the 
point of view of the learning processes. This decision means a choice between different possible consequences. Therefore, the computer feedback model has to represent two aspects: uncertainty and rational decisions.

We use the influence diagrams to represent this decision. In the influence diagram [7], there are decision nodes and utility nodes. The inference allows selsecting a knowledge element as target, the decision node then contents a list of candidate elements. In order to apply the inference in the diagram, we defined the apprenticeship utility function (detailed in [5]) for the utility node. This function $\operatorname{Uapp}(\mathrm{Ci}, \mathrm{E})$ calculates the utility to choose an element of knowledge $\mathrm{Ci}$ as target of feedback in taking into account the agent knowledge model.

The inference in the diagram takes into account the probabilities resulting from the knowledge diagnosis and it is based on the utility theory from the decision analysis domain to calculate the estimated utility for each decision.

\section{Conclusion}

For us the main challenge is to achieve adequate realism for the design of TEL in medical education. It needs to take into account the relation between knowledge characteristics, learning situations and theirs computational models.

Our architecture and methodology allow us a progressive validation. Indeed, we are able to validate each agent separately. For the student learning resources, the computer representations are a close world well specified. Consequently, the validation is related to the completeness and the usability factors.

For the knowledge domain, the model has to take into account the evolution of the knowledge extraction. The validation is related to the expressiveness and the adequacy factors.

For the empirical dimension (diagnosis and didactical decision agents) we define a gold standard validation where we define a set of scenarios with a set of correct (input, output) pairs. Finally for the decision agent, we propose a sensitivity analysis: checks whether the best decision is sensitive to small changes.

We specify and validate our computer models in interaction with two kinds of experts (medical and didactical). In future works, we will refine our model from real data in order to improve our model structure, the conditional probability and the decisions factors.

In addition, we will use the design methodology and the generic parts (diagnosis and decision process) in other domains related to professional training. In particular, we work in other medical domain (urology) and in airline pilot training domain.

Finally, the architecture and computer representation allow us an iterative methodology in order to take into account news forms of knowledge. At present, we work in perceptive and gestural knowledge, and our work hypothesis is that is possible to use the same knowledge model and computational representations with new interactions forms (haptic and audio).

\section{References}

[1] Balacheff, N. (1995). Conception, Connaissance et Concept. In D. Grenier (Eds) Séminaire Didactique et Technologies Cognitives en Mathématiques (pp. 219-244).

[2] Blavier A., Gaudissart, Q., Cadière, G.B., \& Nyssen, A.S. (2007). Comparison of learning curves in classical and robotic laparoscopy according to the viewing condition, American Journal of Surgery, 194, 115-121.

[3] Brousseau G. (1997). Theory of Didactical Situations. Dordrecht: Kluwer Academic Publishers edition by $\mathrm{N}$. Balacheff, M. Cooper, R. Sutherland, \& V. Warfield.

[4] Minh Vu C., Luengo V., Vadcard L., \& Mufti-Alchawafa D. (2007), A Framework for Building Intelligent Learning Environments. AIED Applications in Ill-Defined Domains.

[5] Mufti-AlchawafaD., La représentation informatique de la prise de décision didactique. Premières Rencontres JeunesChercheurs sur les EIAH. Evry, France (2006).

[6] Romero C, Ventura S, Gibaja EL, Hervás C., \& Romero F. Web-based adaptive training simulator system for cardiac life support. In Artificial Intelligence in Medicine. Elsevier. 38(1):67-78, 2006.

[7] Russel S. \& Norvig P. Artificial Intelligence: A modern Approach. Prentice-Hall Series In Artificial Intelligence (2003).

[8] Vadcard L. \& Luengo V. (2005), Réduire l'écart entre formation théorique et pratique en chirurgie. EIAH 2005. Montpellier. 